\title{
Exposure assessment of elemental carbon, ultrafine particles, and crystalline silica at highway toll booths
}

\author{
Jungah Shin ${ }^{1}$, Boowook Kim ${ }^{\dagger}$, Jeonghoon Lee $^{2}$, Joon Sig Jung ${ }^{3}$, Yong Chul Shin ${ }^{4}$, \\ Kyeongmin Lee ${ }^{5}$ \\ ${ }^{1}$ Institute of Occupation and Environment, Korea Workers' Compensation and Welfare Service, Incheon 21417, Republic of Korea \\ ${ }^{2}$ School of Mechanical Engineering, Korea University of Technology and Education, Cheonan 31253, Republic of Korea \\ ${ }^{3}$ Nakdong River Basin Environmental Office, Changwon 51439, Republic of Korea \\ ${ }^{4}$ Department of Occupational Health and Safety Engineering, Inje University, Gimhae 50834, Republic of Korea \\ ${ }^{5}$ Samsung Electro-Mechanics Co., Ltd, Suwon 16674, Republic of Korea
}

\begin{abstract}
Highway toll booth workers have been reported to be at an increased risk of occupational lung cancer. Moreover, insufficient studies have been performed on exposure assessment of workers at highway toll booths. Elemental carbon (EC), black carbon (BC), and respirable crystalline silica (RCS) concentrations were measured at highway toll booths in Gyeongsangbuk-do (Republic of Korea). The particle number (PN) concentration and size distribution of ultrafine particle were measured using three SMPS devices. The average concentration of the EC inside the booth was $3.3 \mu \mathrm{g} / \mathrm{m}^{3}$, with the maximum being $5.8 \mu \mathrm{g} / \mathrm{m}^{3}$. The concentrations of EC were highest for booths that operated exclusively for trucks. The average PN concentration inside the booth was $3.54 \times 10^{4} \mathrm{~cm}^{-3}$, approximately 5 -fold higher than the reference indoor background. The average BC concentration in the booths were approximately $8 \mu \mathrm{g} / \mathrm{m}^{3}$, and the instantaneous peak concentration was $271 \mu \mathrm{g} / \mathrm{m}^{3}$. The RCS was below the detection limit in all samples. This study revealed that toll workers were most frequently exposed to diesel engine particle less than $100 \mathrm{~nm}$, with an extremely high respiratory deposition rate. Therefore, a respiratory protection program is necessary to safeguard these workers against vehicle-related pollutants.
\end{abstract}

Keywords: Crystalline silica, Diesel engine particle, Elemental carbon, Particle number concentration, Particle size distribution, Toll station workers

\section{Introduction}

As of 2017, the Korea Expressway Corporation, which manages the toll road network in South Korea, had 30 operating routes with a total length of $4,113 \mathrm{~km}$ (41 km in 10 lanes, $434 \mathrm{~km}$ in 8 lanes, $503 \mathrm{~km}$ in 6 lanes, and 3,135 km in 4 lanes) and 604 $\mathrm{km}$ in 8 private sector routes.

According to the 2015 data, 5,495 workers were employed at 369 toll stations (335 on the Korea Expressway Corporation and 34 on private roads) in Korea [1].; further, according to 2017 data [2], Roughly 8,000 workers operate in 420 toll stations, most of whom are women. Demographics indicate that most workers are female. Henschke and Miettinen [3] show that women are at a greater risk of lung cancer, rendering the studies on the exposure of workers to various pollutants and carcinogens particularly important. The nationwide count of toll gates includes highways operated by private companies such as the Gyeongchun Expressway, and the general highway operated by the Korea Highway Corporation, and the Namsan 1 and 3 tunnels as well as the Woomyeonsan tunnel in Seoul.

Workers at toll booths are exposed to the smoke generated from numerous vehicles that transit through these tolls throughout the day; further, they are also exposed to the atmospheric particlates matter (PM).

In 2012, the International Agency for Research on Cancer (IARC) designated diesel engine emission as a Group 1 carcinogen, indicating that there is sufficient evidence of its carcinogenicity in humans. PM was also classified as a Group 1 carcinogen in 2013 [4].
This is an Open Access article distributed under the terms of the Creative Commons Attribution Non-Commercial License (http://creativecommons.org/licenses/by-nc/3.0/) which permits unrestricted non-commercial use, distribution, and reproduction in any medium, provided the original work is properly cited.

Copyright (C) 2021 Korean Society of Environmental Engineers
Received July 03, 2020 Accepted October 09, 2020

${ }^{\dagger}$ Corresponding author

Email: labor7@gmail.com

Tel: +82-032-540-4968 Fax: +82-032-540-4997

ORCID: 0000-0001-6869-2320 
The substances emitted from vehicle engines are mixtures of particulate and gaseous substances from incompletely burned fuels and lubricants. Gasoline engines produce higher emissions of polycyclic aromatic hydrocarbons (PAHs), carbon monoxide, and carbon dioxide than diesel engines, but exhibit significantly lower emissions of nitrogen oxides and PM [5]. The main components of diesel engine particle (DEP) are elemental carbon (EC) and PAHs. In diesel engine exhaust, a maximum of three benzene rings are generated, alongside low molecular weight PAHs. In gasoline engine exhausts, benzo[a] pyrene and dibenz[a,h]anthracene are generated [6, 7].

Diesel engine exhaust (DEE) is harmful to the human body because of the toxic complex components of many gaseous and particulate matters including PAHs. In addition, the deposition of particulate matter in the respiratory system depends on the particle size. This is explained by the deep penetration and high rate of respiratory deposition (cited in archive toxicity). The particle size of DEP varies depending on engine load, which is determined by vehicle acceleration, the ratio of engine running and stopping, and catalyst use, amongst other factors; however, because the geometric mean diameter of DEP is very small (less than $100 \mathrm{~nm}$ ), DEP gives rise to concerns about health effects by nanoparticles $[5,7,8]$.

Incomplete combustion of diesel fuel in engines is known to generate reactive and resonance-stabilized radicals, along with hydrocarbons such as acetylene and PAHs. Subsequently, these radicals undergo chain reactions to form larger and more stable radicals. These radicals produce a nuclei with a diameter of 1 to $4 \mathrm{~nm}$ and the hydrocarbons and radicals in the vicinity are quickly attached to the nuclei, forming a soot nanoparticle with a diameter of 10 to $50 \mathrm{~nm}$. In addition, it is known that hydrocarbons such as $\mathrm{PAH}$, nitrogen 'oxides, sulfur oxides, and heavy metals adhere to the surface of these soot nanoparticles, and these soot nanoparticles are also aggregated to become larger particles [9]. On the other hand, the lung deposition rate of particles depends on the aerosol concentration in the ambient environment and the mode diameter of the particles. Additionally, the lung deposition particle fraction increases with decreasing diameter of the main mode of a particle size distribution [10]. Therefore, when evaluating exposure to DEP, it is possible to obtain a more in-depth exposure evaluation by analyzing the EC component and the size distribution as well as the number concentration of UFP [10-12]. Elemental carbon are thermally stable carbonaceous particles and normally quantified by an evolved gas analysis such as an OCEC Analyzer. Black carbon is similar to elemental carbon in that both are carbonaceous particles produced from the combustion process in flames and engines. Black carbon is usually measured using a filter-based light absorption technique or photothermal spectroscopy [5].

Ultrafine particles (UPFs) generally refer to particles smaller than $100 \mathrm{~nm}$ [13] and account for most of the particle number (PN) concentration measured by a Scanning Mobility Particle Sizer (SMPS) device. Road vehicles are the primary source of UFP emissions in urban pollution hotspots [14].

Toll booth workers are repeatedly exposed to vehicle emission as automobiles slow down and accelerate in front of the toll booth. In addition, booth windows remain open for the majority of the working hours; therefore, workers experience continuous exposure to vehicle emissions and PM in the atmosphere.
Recently, there have been increasing cases of occupational lung cancer due to DEE exposure, and there are concerns about the relationship between PM and diseases amongst outdoor workers, such as municipal household waste workers [15], shipyard transporter signal workers [16], and construction laborers [17]. Previous studies on the exposure of toll workers to hazardous materials have been primarily conducted on the $\mathrm{PM}_{2.5}$ and $\mathrm{PM}_{10}$ [18]. Studies on PN concentration and size distribution have been rarely reported; in particular, few studies have investigated the concentration of respirable crystalline silica (RCS) as a carcinogen for lung cancer [19].

In addition, according to Jancsek-Turóczi et al. [20], the mineral phase composition of resuspended road dust at three kerbside locations in Veszprém, Hungary contained 10 to $20 \%$ crystalline silica (as quartz). In another study by Gunawardana et al. [21] the road dust consist primarily of soil derived minerals (60\%) with quartz averaging $40-50 \%$ and remainder being clay forming minerals of albite, microcline, chlorite and muscovite originating from surrounding soils. Therefore, the toll gate workers may be at risk of exposure to crystalline silica contained in resuspended dust on the road.

Therefore, the objectives of this study are to evaluate the exposure level of RCS and DEP on workers in toll booths through the level of surrogates, EC, black carbon (BC), and PN concentration, and to measure the particle size distribution of airborne UFP.

\section{Material and Methods}

\subsection{Study Sites}

This study conducted environmental measurements for DEP and RCS that the toll workers were exposed to at five booths of two tollgates, denoted as Gate A and Gate B, on the Gyeongbu Line highway on February 2, 2015. Interviews with workers and employers were conducted to obtain information on the traffic volume, lane characteristics, and air curtain usage. Workers were allowed to work in three shifts, eight hours a day, which were scheduled as follows: first shift from 06:30 to 14:30, middle shift from 14:30 to $22: 00$, and last shift from 22:00 to $06: 30$.

Measurements of the air quality at Gate A were performed both inside and outside for a single exit booth, inside the other three exit booths, and at the entrance gate (boothless gate). Measurements were also made inside and outside the office building environment at Gate A. At Gate B, measurements were performed at the inside of the four exit booths and at the entrance gate, similar to Gate A.

The toll gate entrance is divided into two vehicle types - freights and general vehicles. General vehicles include general passenger cars, vans with less than 16 passengers, freight cars with less than 2.5 tons, and light-weight vehicles.

The measurement position inside the booth was close to the breathing position of the workers, and the measurement positions outside the booth and outside the office building were approximately $1.0 \mathrm{~m}$ above the ground (Fig. 1). The PN concentration as a reference was also measured at inside of our research institute located in Incheon. 


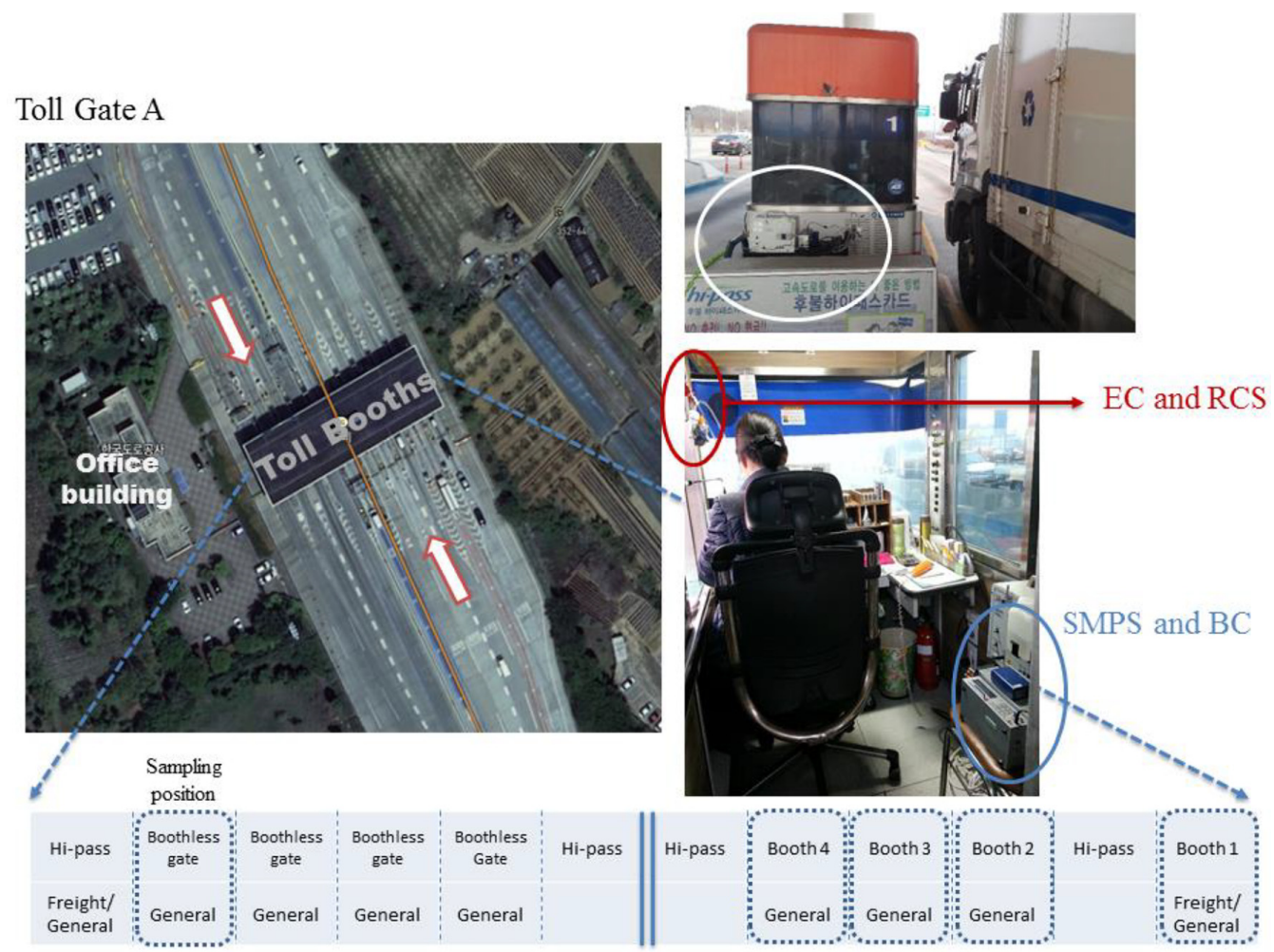

Fig. 1. Photos of the sampling location inside and outside the booth at Gate A.

\subsection{Measurement and Analysis Methods}

We used $37 \mathrm{~mm}$ quartz filters preloaded in three-piece clear plastic cassettes (Cat.No. 225-401, SKC Inc., USA) with respirable dust cyclone (GK2.69, BGI Inc., Waltham, MA, USA) using a sampling pump (Aircheck XR5000, SKC Inc., Eighty Four, Pa., USA). The GK2.69 cyclone has a 50\% cut point of $4 \mu \mathrm{m}$ at a flow rate of $4.2 \mathrm{~L} / \mathrm{min}$. The EC concentrations were obtained from the samples using a Lab OCEC Analyzer (Sunset Laboratory Inc., USA) according to the National Institute for Occupational Safety and Health (NIOSH) Method 5040 [22]. The analysis accuracy was confirmed through the analysis of external standard samples (Sunset Laboratory Inc., USA). The limit of detection of the analyzer was $0.15 \mu \mathrm{g} / \mathrm{cm}^{2}$, and all sample measurements for this study exceeded the detection limit. LOD was calculated directly in our laboratory using the NIOSH guidelines for air sampling and analytical method development and evaluation [23].

The RCS concentration was analyzed according to the NIOSH 7500 guidelines [24]. The repirable dust samples were collected on the polyvinyl chloride filters (diameter $37 \mathrm{~mm}$, pore $5.0 \mu \mathrm{m}$ ) using GK2.69 cyclone in combination with AirChek XR5000 pump. The samples were analyzed by X-ray diffraction (D8 Advance, Bruker Corporation, Ettlingen, Germany).

The analysis took place at the Institute of Occupation and Environment, Korea Workers' Compensation and Welfare Service, participating in the American Industrial Hygiene Association Proficiency Analytical Testing program.

Realtime, continuous measurement $\mathrm{BC}$ mass concentration was measured using the four MicroAeth (AE51, TSI Inc., US) at a total of 4 locations inside and outside booth 1 and outside of the office building at Gate A and inside of booth 1 at Gate B. Data was recorded from approximately 7:30 to 14:00 at Gate A, and from approximately 8:55 to 14:30 at Gate B. The measurement interval for the MicroAeth was $30 \mathrm{~s}$, and the pump flow rate was $0.1 \mathrm{~L} / \mathrm{min}$. All BC instruments were replaced with new filters and then measured.

For the measurement of the realtime number concentration and particle size distribution of the PM at both study sites, an SMPS (Model 3910, TSI Inc., US) was used. Particles ranging in size from 0.01 to $0.42 \mu \mathrm{m}$ were divided into 13 channels. Three SMPSs were used to perform measurements at three locations, which were inside and outside the toll booths at Gate A and outside office building A. The SMPS is calibrated annually by the manufacturer (US TSI Inc.) to maintain the accuracy of the results, and the particle density of all three devices was set to $1.2 \mathrm{~g} \mathrm{~cm}^{-3}$.

\subsection{Meteorological Data}

Meteorological factors, including temperature $\left({ }^{\circ} \mathrm{C}\right)$, humidity $(\%)$, wind speed $(\mathrm{km} / \mathrm{h})$, and wind direction $\left(^{\circ}\right)$, all of which can affect toll booths, were supplied by the Automatic Weather System of the Korea Meteorological Administration. We documented temperature, humidity, wind speed, and the wind direction each minute from 7:30 to 14:00 on the measurement day. The arithmetic means of temperature, humidity, and wind speed were used for statistical analysis to confirm their effects.

\subsection{Data Analysis}

The minimum, median, and maximum values of PN concentration 
(SMPS) and BC concentration were calculated using descriptive statistics. A distribution of the SMPS and BC measurement results on a log probability plot resulted in linearity. Thus, the geometric mean (GM) concentration was calculated after the logarithmic conversion. Pearson's correlation analysis was performed to determine the correlation between BC and PN concentration and a correlation analysis between meteorological factors and BC concentration was also conducted.

\section{Results}

\subsection{Elemental Carbon and Black Carbon Concentrations}

The concentration of EC measured inside 8 toll booths was 3.3 $\mu \mathrm{g} / \mathrm{m}^{3}$ on average, with a minimum concentration of $1.85 \mu \mathrm{g} / \mathrm{m}^{3}$ and maximum concentration of $5.84 \mu \mathrm{g} / \mathrm{m}^{3}$.

One toll booth was open all day at Gate A, and the concentrations of EC and BC, indicators of DEP, were the highest in Booth 1, open exclusively for trucks. The average EC concentration inside Booth 1 was $3.4 \mu \mathrm{g} / \mathrm{m}^{3}$, which was $70 \%$ of the concentration outside of the Booth $\left(4.8 \mu \mathrm{g} / \mathrm{m}^{3}\right)$. The GM concentration of BC inside Booth 1 was $7.3 \mu \mathrm{g} / \mathrm{m}^{3}\left(2.2-60.7 \mu \mathrm{g} / \mathrm{m}^{3}\right)$, which was $88 \%$ of the $\mathrm{GM}$ concentration of BC outside Booth 1 (Table 1 shows the value as $\left.8.3 \mu \mathrm{g} / \mathrm{m}^{3}\left[0.2-242.3 \mu \mathrm{g} / \mathrm{m}^{3}\right]\right)$. The average EC concentration at Booth 2, open all day along with Booth 1 , was $2.8 \mu \mathrm{g} / \mathrm{m}^{3}$, which was the second highest concentration measured after Booth 1. It was expected that the EC concentration at Booth 2 was lower because it was a gate for general vehicles, unlike Booth 1 which was open exclusively to trucks. It is likely that the emissions generated by general vehicles is relatively less compared to that by trucks.

On the other hand, the average EC concentration at Booth 3, open for only one hour in the morning for 347 general vehicles, was $1.6 \mu \mathrm{g} / \mathrm{m}^{3}$ which was $47 \%$ lower than Booth 1 . At Booth 4 , without any vehicle traffic, the average EC concentration inside the booth was $2.1 \mu \mathrm{g} / \mathrm{m}^{3}$ which was $62 \%$ lower than Booth 1 . The EC concentration at the entrance gate without a booth was relatively low at $2.2 \mu \mathrm{g} / \mathrm{m}^{3}$, despite being open only for trucks and having a large amount of traffic.

Gate B showed a similar trend to Gate A. The average EC concentration was the highest at Booth 2, which was open exclusively to trucks and experienced heavy traffic, at $5.8 \mu \mathrm{g} / \mathrm{m}^{3}$ and lowest at Booth 4, which had no traffic, at $1.9 \mu \mathrm{g} / \mathrm{m}^{3}$. The average and maximum BC concentration in Booth 1 was $8.8 \mathrm{ug} / \mathrm{m}^{3}$ and 271 $\mathrm{ug} / \mathrm{m}^{3}$, respectively.

\subsection{Particle Number Concentration and Particle Size Distribution}

Table 2 and Fig. 2 show PN concentration levels for different sampling sites. The average PN concentration inside the booth was $3.54 \times 10^{4} \mathrm{~cm}^{-3}$, and the maximum value was $2.48 \times 10^{5} \mathrm{~cm}^{-3}$, which was approximately 20 times higher than the minimum value

Table 1. Elemental Carbon and Black Carbon Concentration at Gate A and Gate B

\begin{tabular}{|c|c|c|c|c|c|c|c|}
\hline \multirow{2}{*}{ Toll Gate } & \multirow{2}{*}{ Sampling location } & \multirow{2}{*}{ Measuring position } & \multirow{2}{*}{ Vehicle type } & \multirow{2}{*}{ Gate opening } & \multirow{2}{*}{ Traffic volume } & \multicolumn{2}{|c|}{ DEP $\left(\mu \mathrm{g} / \mathrm{m}^{3}\right)$} \\
\hline & & & & & & EC & BC \\
\hline \multirow{6}{*}{ A } & Bonth 1 & In & \multirow{2}{*}{ Freight } & \multirow{2}{*}{ All day } & \multirow{2}{*}{989} & 3.4 & $7.3(2.3 \sim 60.7)$ \\
\hline & Booth 1 & Out & & & & 4.8 & $8.3(0.2 \sim 242.3)$ \\
\hline & Booth 2 & In & General & All day & 1,116 & 2.8 & - \\
\hline & Booth 3 & In & General & Partially 1 & 347 & 1.6 & - \\
\hline & Booth 4 & In & General & Blocked & 0 & 2.1 & - \\
\hline & Entrance gate & Out & Freight & All day & 795 & 2.2 & - \\
\hline \multirow{5}{*}{ B } & Booth 1 & In & Freight & Partially 2 & 1,120 & 4.2 & $8.8(1.2 \sim 271.3)$ \\
\hline & Booth 2 & In & Freight & All day & 1,099 & 5.8 & - \\
\hline & Booth 3 & In & General & Partially 3 & 444 & 2.4 & - \\
\hline & Booth 4 & In & General & Blocked & 0 & 1.9 & - \\
\hline & Entrance gate & Out & Freight & All day & 993 & 2.7 & - \\
\hline & Mean & & & & & 3.4 & \\
\hline \multicolumn{4}{|c|}{ Inside of office building } & - & - & 1.3 & - \\
\hline \multicolumn{4}{|c|}{ Outside of office building } & - & - & 1.6 & $4.8(0.5 \sim 233.2)$ \\
\hline
\end{tabular}

\section{Booth: toll booth}

Entrance gate: Boothless gate (receive an automatic ticket and pass right away)

Measuring position In : Inside the booth, OUT : outside the booth

Concentration in booth except control group

Sampling location : Booth number

Partially 1: opening only 08:00 09:00, 2: Closed 09:00 10:00, 11:30 13:00, 3: Closed 14:30 15:00

Traffic volume : number of cars

Office building: approximately $30 \mathrm{~m}$ from the toll gate A 
Table 2. Number Concentration and Mean Particle Size Inside and Outside the Toll Booth at Gate A

\begin{tabular}{lcc}
\hline Measuring position & Geometric mean number concentration (range) & Mean particle size(range) \\
Inside booth 1 & $3.54 \times 10^{4}\left(1.21 \times 10^{4} \sim 2.48 \times 10^{5}\right)$ & $46(24 \sim 76)$ \\
Outside booth 1 & $6.05 \times 10^{4}\left(1.10 \times 10^{4} \sim 2.95 \times 10^{6}\right)$ & $51(16 \sim 149)$ \\
Outside of office building & $3.13 \times 10^{4}\left(1.04 \times 10^{4} \sim 1.39 \times 10^{5}\right)$ & $58(25 \sim 93)$ \\
Control & $6.55 \times 10^{3}\left(4.62 \times 10^{3} \sim 1.26 \times 10^{4}\right)$ & $64(55 \sim 75)$ \\
\hline
\end{tabular}

Unit of number concentration: particles $/ \mathrm{cm}^{3}$

Unit of particle size: $\mathrm{nm}$

Control: Indoor background of our Research Institute

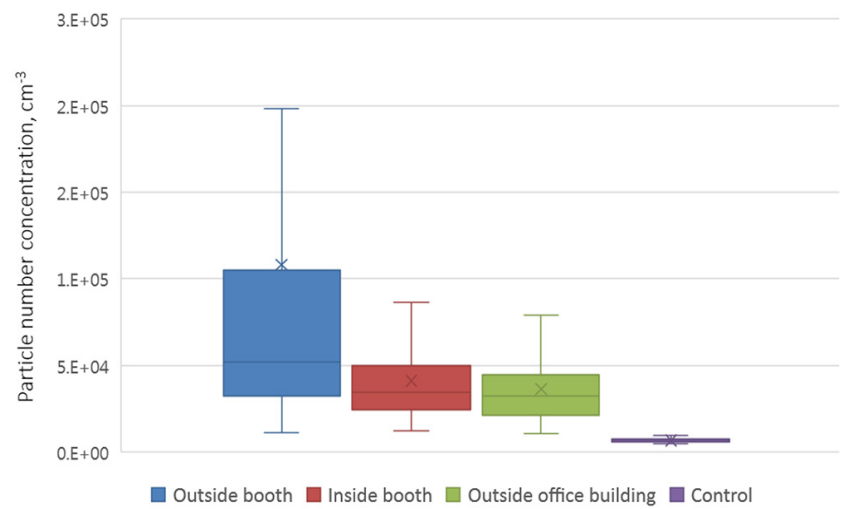

Fig. 2. Particle number concentration levels for different sampling sites. Sampling site of the control is indoor space at our Research Institute. The box and whisker plot show the lowest, lower quartile, median, upper quartile, and maximum values.

of $1.21 \times 10^{4} \mathrm{~cm}^{-3}$. The average PN concentration outside the booth was $6.05 \times 10^{4} \mathrm{~cm}^{-3}$, which was 1.7 times higher than the average concentration inside the booth. The minimum value was $1.10 \times$ $10^{4} \mathrm{~cm}^{-3}$, which was $10 \%$ lower than inside the booth, and the maximum value was $2.95 \times 10^{6} \mathrm{~cm}^{-3}$, which was approximately 12 times higher than inside. The average PN concentration measured outside the office building was $3.13 \times 10^{4} \mathrm{~cm}^{-3}$, which was $88 \%$ of the average PN concentration inside the booth, but the highest concentration was $1.39 \times 10^{5} \mathrm{~cm}^{-3}$, which was much lower, at $56 \%$ of the maximum concentration inside the booth. The indoor background PN concentration of our Research Institute (in another region) was approximately $25 \%$ of the concentration in the air outside the tollgate office building.

The particle size distribution outside the booth varied in shape depending on the PN concentration. As for the size distribution outside the booth, when the PN concentration was equivalent to the background atmospheric concentration in the absence of vehicles, the mode diameter was $115 \mathrm{~nm}$. Bimodal size distribution was observed when the PN concentration is at its median value. The particle size distribution changed to a bimodal distribution with peaks at particle diameters of 27 and $120 \mathrm{~nm}$. When the PN concentration was at its highest, unimodal size distribution with a mode diameter of $20 \mathrm{~nm}$ was observed (Fig. 3).

The particle size distribution inside the booth exhibited similar behavior to the size distribution outside the booth. As for the size distribution inside the booth, when the PN concentration was at a maximum a unimodal size distribution was formed, with a mode diameter of $27 \mathrm{~nm}$. In contrast, when the PN concentration was at the median value, the size distribution changed to a bimodal distribution with a mode diameter of 37 and $87 \mathrm{~nm}$. When the PN concentration was at a minimum, the size distribution became unimodal again with the peak at $87 \mathrm{~nm}$. Interestingly, smaller particles were observed inside the booth, meaning that diesel particles transported inside the booth remained stagnant while the diesel particles outside the booth were scavenged along with air stream due to blowing wind.

The particle size distribution measured outside the office building at low PN concentration was similar to the particle size distribution at atmospheric background level with a mode diameter of $115 \mathrm{~nm}$. When the PN concentration was at its median value, a bimodal distribution with mode diameters of $15 \mathrm{~nm}$ and $36 \mathrm{~nm}$ was observed. At the highest PN concentration, a multimodal distribution was observed because both diesel particles and atmospheric background particles were present, with peaks at 20 and $115 \mathrm{~nm}$. These results imply that the vehicle emission generated on the highway affected the air quality of office building $30 \mathrm{~m}$ away from vehicle traffic.

\subsection{Real-Time Particle Number Concentration and Black Carbon}

Fig. 4 shows the variation in PN concentration and black carbon levels inside the Booth 1 at Gate A over the sampling period. The PN concentration traced BC concentration well. There was statistically significant correlation between the PN concentration and BC concentration confirmed through Pearson's correlation analysis. The correlation coefficient was $0.54(\mathrm{p}<0.01)$.

\subsection{Crystalline Silica}

As a result of scanning the collected respirable dust by XRD, trace amounts of quartz and silicate minerals were found in some samples, but they were below the detection limit so could not be used for quantitative analysis.

\subsection{Meteorological Influences}

During the measurement time, the mean value (standard deviation, $\mathrm{SD}$ ) of the temperature, humidity, wind speed, and wind direction were $-0.76^{\circ} \mathrm{C}$ (4.46), $55.32 \%$ (19.17), $0.416 \mathrm{~m} / \mathrm{s}(0.425)$ and $136.8^{\circ}$ (131.4), respectively. 


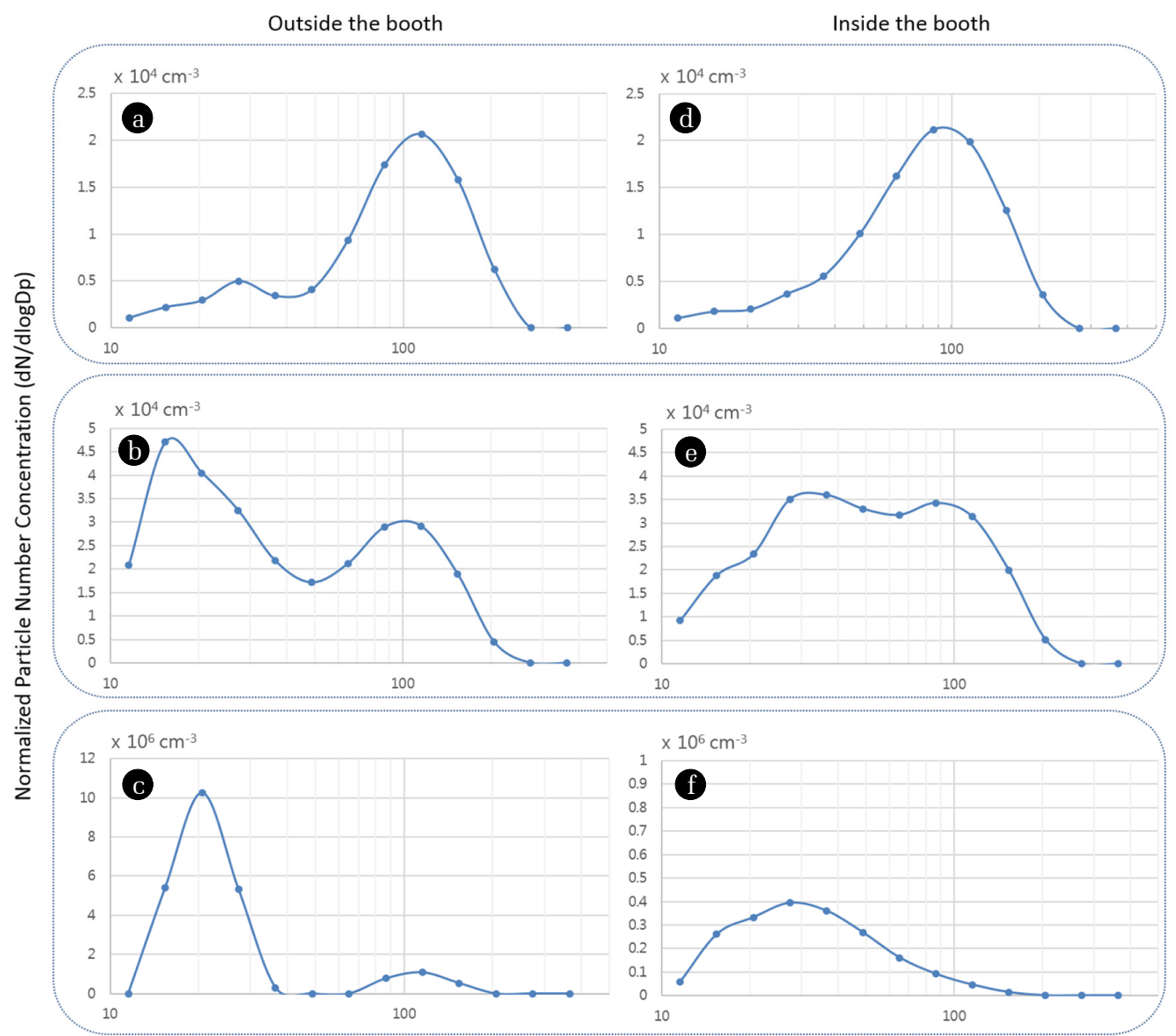

Particle diameter $(\mathrm{nm})$

Fig. 3. (a)-(c) show the results outside the booth, and (d)-(f) show the results inside the booth. The particle number size distribution as determined according to the number concentration at different particle diameters. (a) and (d) The particle size distribution is unimodal at the minimum number concentration. (b) and (e) The particle size distribution is bimodal when the number concentration is at its median value. (c) and (f) The particle size distribution returns to a unimodal distribution at the maximum number concentration.

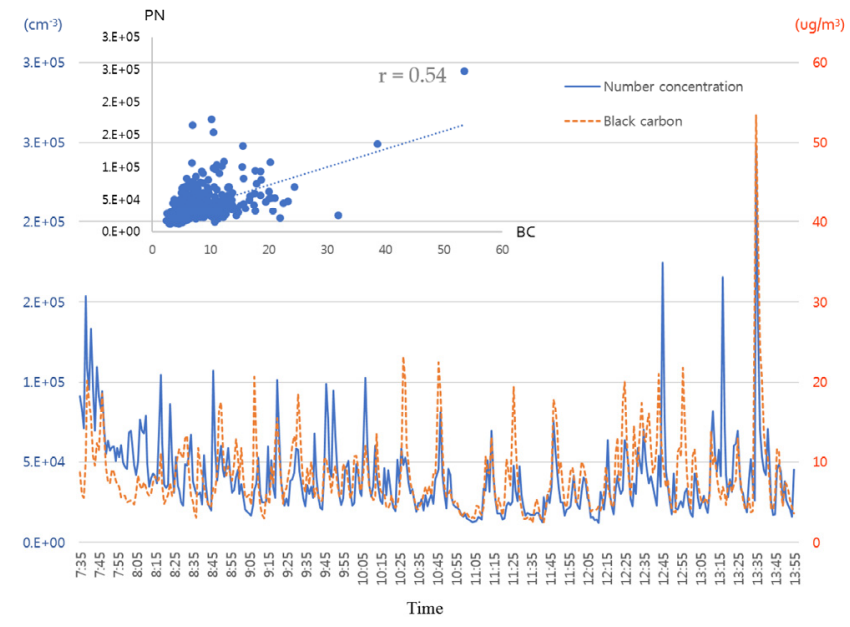

Fig. 4. Time-dependent concentration of particle number (PN) concentration and black carbon (BC) monitored in Gate A for sampling period, and the correlation between $\mathrm{PN}$ and $\mathrm{BC}$ (inset).
BC concentration did not show a significant correlation with meteorological factors. The correlation coefficients between BC measured per minute and temperature, humidity, wind speed, and wind direction were $0.047,-0.043,0.006$, and -0.036 respectively ( $\mathrm{p}>0.05)$.

\section{Discussion}

In June 2012, the IARC classified DEE as Group 1 carcinogenic agents, resulting in occupational lung cancer being linked to exposure to DEE in Korea. The number of cases where workers have applied to the government for industrial accident compensation have increased since 2012 .

A study by Kim et al. [25] found that $9.7 \%$ of the general Korean population are exposed to carcinogens. The population attributable fraction (PAF) of total cancer was $1.1 \%$ and lung cancer was $7.0 \%$. In another study by Leem et al. [26], the combined proportion of definite and probable occupational lung cancer among all lung 
cancers investigated over the four-year (2006-2009) study period was $11.7 \%$. The main carcinogens include asbestos, RCS, radon, PAHs, DEE, chromium, and nickel. In addition, according to Choi et al. [27], the total number of Korean workers exposed to DEE was estimated to be 417,034 in 2013 (2.2\% of the total labor force).

However, data on the concentration of DEE and characteristics of vehicle related particles in various workplaces is lacking.

Previous studies conducted at highway tolls showed that the mass median diameter (MMD) of suspended PM in the air was $0.78 \mu \mathrm{m}$ on average, measured using a high-volume cascade impactor (Anderson Sierra-352, US) at highway tolls in 1999 [28]. However, the MMD measured in downtown Seoul (Bulgwang-dong) was 3.2-3.5 $\mu \mathrm{m}$, and $4.6 \mu \mathrm{m}$ during the yellow dust event. This means that highway toll stations are mainly polluted by vehicle emissions with small particle sizes. Additionally, evaluation of the concentration of PAHs in the same study showed that dibenzo[a,h]anthracene, which is known to have high toxicity among PAHs substances, had an average concentration of $1.64 \mu \mathrm{g} / \mathrm{m}^{3}$, and the representative carcinogen, benzo[a]pyrene, had an average concentration of $5.67 \mu \mathrm{g} / \mathrm{m}^{3}$. This concentration was higher than in some urban areas such as Seoul [29].

Nam and Phi [18] evaluated $\mathrm{PM}_{10}$ concentration at toll gate booths. In 2020, Nam et al. [30] investigated the chemical composition of the total dust using $\mathrm{XRF}$, and measured concentrations of $\mathrm{PM}_{10}$, $\mathrm{PM}_{2.5}$, and $\mathrm{PM}_{1}$ using direct-reading devices. There is a possibility of exposure to the carcinogen crystalline silica because its presence was analyzed by XRF in a total dust sample scattered around the toll station with high $\mathrm{SiO}_{2}$ content. Additionally, a study in India showed that $\mathrm{Si}$ was $60 \%$ in the urban $\mathrm{PM}_{2.5}$ elemental component [31].

This study uses XRD to analyze the crystal structure of crystalline silica unlike XRF, which analyzes chemical components. However, in our work, RCS was not detected in all samples (Below detection limit).

In contrast, according to Kim et al. [32] who investigated the concentration of RCS in the air in some regions of Korea, the average concentration per year was $0.8 \mu \mathrm{g} / \mathrm{m}^{3}$, and the average concentration in spring was $1.3 \mu \mathrm{g} / \mathrm{m}^{3}$. When there was a yellow dust event, the average concentration increased to $8.8 \mu \mathrm{g} / \mathrm{m}^{3}$. In addition, the concentration of RCS at the time of Yellow Dust Warning with a fine dust concentration of $800 \mu \mathrm{g} / \mathrm{m}^{3}$ is estimated to be $33 \mu \mathrm{g} / \mathrm{m}^{3}$, exceeding $25 \mu \mathrm{g} / \mathrm{m}^{3}$ of the American Conference of Governmental Industrial Hygienists Threshold Limit Value criterion. However, in this study, as part of the measurement of the working environment, it was measured according to the NIOSH 7500 method, so the amount of collected air volume was approximately $1700 \mathrm{~L}$ and the lower detection limit (LOD) was $3.4 \mu \mathrm{g} / \mathrm{m}^{3}$. Therefore, the concentration of crystalline silica in the air on the day of the toll booths survey could not have exceeded the LOD because levels were less than $3.4 \mu \mathrm{g} / \mathrm{m}^{3}$. However, a respiratory mask is necessary as the workers can be exposed to crystalline silica above the LOD on dusty days or when the wind is strong and the distribution of sediment dust is severe.

In a study by Kim et al. [33], a black carbon assessment was conducted at a toll gate at a university in Seoul. The concentration of $\mathrm{BC}$ was found to be $2.44 \mu \mathrm{g} / \mathrm{m}^{3}$, which was 1.4 times higher than that of the control group at $1.75 \mu \mathrm{g} / \mathrm{m}^{3}$. It is thought that black carbon concentration is higher in proximity to moving traffic, especially when a truck or an old vehicle using diesel fuel passes by, when the toll gate worker is exposed to an instantaneous high concentration of BC.

A relatively small number of studies have used SMPS to study PN concentration and particle size distribution at highway tolls in Korea. International studies have used SMPS to evaluate factors such as PN concentration and particle size distribution. A study [34] evaluated how these factors varied depending on the distance from major highways in Los Angeles, USA. As the distance from the highway increased, it was observed that the concentration of the smallest particle sizes decreased, and disappeared at $90 \mathrm{~m}$. In addition, the concentration of $\mathrm{PN}$ in general decreased with distance. The average concentration of $\mathrm{PN}$ at the nearest measurement point, $30 \mathrm{~m}$ from the highway, was $1.5 \times 10^{5} \mathrm{~cm}^{-3}$, and the average concentration of $\mathrm{BC}$ was $5.4 \mu \mathrm{g} / \mathrm{m}^{3}$ which was similar to the concentration outside the booth in this study. In our study, the average PN concentration was $1.0 \times 10^{5} \mathrm{~cm}^{-3}$ and the average of BC concentration was $8.3 \mu \mathrm{g} / \mathrm{m}^{3}$. The PN concentration is considered to be higher in Los Angeles due to the substantially high traffic volume. The concentration of BC was higher in this study because the measurement location was a lane dedicated to freight cars.

In this study, the average BC concentration inside two toll booths was 7 to 9 times higher than the BC general indoor background concentration of $1 \mu \mathrm{g} / \mathrm{m}^{3}$ [35].

The average $\mathrm{BC}$ concentration was 2.2 times higher than the elemental carbon concentration in this study. This is comparable to the results of Lee et al. [15] who found a BC concentration that was 1.99 times higher than the EC concentration. The presence of black carbon may be overestimated in our study because light absorption occurs in organic materials such as brown carbon in addition to elemental carbon components in the measuring device [36].

DEP and RCS flowing into the toll booths may be affected by meteorological conditions because the toll booths are located outdoors. Real-time temperature, humidity, wind speed, and wind direction on the day of the measurement were not related to the BC concentrations for real-time DEP confirmation. The concentration of PM outdoors may increase when the wind speed is slow, and on a day with a high wind speed, the exposure level may be lower due to diffusion [37, 38]. According to Shin et al. [15], although the type of diesel engines are different from this study, it was confirmed that workers exposed to DEP outdoors were exposed to high concentrations on days when wind speeds were lower than $1.3 \mathrm{~m} / \mathrm{s}$. In this study, the average wind speed was lower than $1.3 \mathrm{~m} / \mathrm{s}$, but the change of BC concentration according to the real-time wind speed change could not be confirmed. Although the toll booth is located outdoors, it has a roof and vehicles continuously move in one direction along the one-lane road next to the booth. This seems to be because DEP was more influenced by the wind direction and speed. On the other hand, on days with strong wind speed, the concentration of DEP can be diluted and lowered as in other studies [37, 38].

This study is the result of only one day of measurements at two toll gates in South Korea. Therefore, this study is limited in its ability to represent the level of diesel exhaust exposure to all toll gate workers globally. The short measurement period in this study also inhibited the detection of crystalline silica. A larger variety of toll gates require additional investigation and measurements should be conducted for longer durations to determine crys- 
talline silica exposure levels.

\section{Conclusion}

This study is the first to assess the exposure of highway toll workers to DEP and RCS in Korea. The objectives of this study are to evaluate the exposure level of RCS and DEP on workers in toll booths through the level of surrogates, EC, BC, and PN concentration, and to measure the particle size distribution of UFP.

The RCS concentration was below the detection limit. However, caution is required because roadside sedimentary dust is re-dispersed on windy days and may be exposed to RCS during yellow dust periods.

Workers in the toll booths of highways are continuously exposed to vehicle emissions, including diesel exhaust, and intermittently exposed to extremely high concentrations of diesel emissions. Results of the particle size distribution in the toll booths indicated that the most common particles had diameters in the range of 20-70 $\mathrm{nm}$; these particles have a very high respiratory deposition rate.

In addition, the difference in the concentration of DEP exposure to workers inside the booth and outside the booth was not significant. Therefore, improving the work environment of the toll booths for worker's protection and wearing an N95 respirator is recommended to be incorporated into national policy. Further daily monitoring of vehicle traffic information, meteorological conditions and DEP concentrations that allow for estimates of annual cumulative EC exposure will foster protection of workers' health. We also recommend establishing an Occupational Exposure Limit and reduction controls against diesel exhaust sources to prevent diseases caused by DEP.

\section{Acknowledgment}

We would also like to thank the reviewers and editors of Environmental Engineering Research for their detailed and useful comments.

\section{Author Contributions}

J.S. (Ph.D. Student) and B.K. (Ph.D.) conceptualized. J.S., B.K. and K.L.(M.S.) conducted measurement and all the experiments. J.-S.J. (Ph.D.) and Y.-C.S. (Professor) reviewed the methodology and validated the technical aspects. B.K., J.L. (Professor) and J.S. wrote original draft. B.K., J.L., and J.S. reviewed and revised the draft. All authors have read and agreed to the published version of the manuscript.

\section{References}

1. Kim HI, Kang DM, Kim JE, et al. A survey on work environment of express tollgate workers. Korea Occupational Safety \& Health Agency Report. 2015. [Korean]

2. Ham JS. 7 times as much fine dust ...After measuring the highway toll booth. JoongAng Ilbo Co. 19. April. 2017. Available from: https://news.joins.com/article/21491538 [Korean]

3. Henschke CI, Miettinen OS. Women's susceptibility to tobacco carcinogens. Lung Cancer 2004;43(1):1-5.

4. International Agency for Research on Cancer (IARC). Agents classified by the IARC monographs [Internet]. IARC. 2012. Available from: https://monographs.iarc.fr/agents-classified-bythe-iarc/

5. Ono-ogasawara M, Smith TJ. Diesel exhaust particles inthe work environment and their analysis. Ind. Health 2004;42:389-399.

6. Marr LC, Kirchstetter TW, Harley RA. Characterizationof polycyclic aromatic hydrocarbons in motor vehicle fuels and exhaust emissions. Environ. Sci. Technol. 1999;33:3091-3099.

7. Miguel AH, Kirchstetter MT, Harley RA. On-roademissions of particulate polycyclic aromatichydrocarbons and black carbon from gasoline anddiesel vehicles. Environ. Sci. Technol. 1998;32:450-455.

8. Kittelson DB. Engines and nanoparticles: a review. J. Aerosol Sci. 1998;29:575-588.

9. Johansson KO, Head-Gordon MP, Schrader PE, Wilson KR, Michelsen HA. Resonance-stabilized hydrocarbon-radical chain reactions may explain soot inception and growth. Science 2018;361(6406):997-1000.

10. Hammer T, Gao H, Pan Z, Wang J. Relationship between Aerosols Exposure and Lung Deposition Dose. Aerosol Air Qual. Res. 2020;20:1083-1093.

11. Kim B, Song DW. Comparison of diesel exhaust particle concentration between large above-underground parking lots. J. Korean Soc. Occup. Environ. Hyg. 2013;23:323-332. [Korean]

12. Lee S, Jankewicz G, Kim JH, Chung KB. A periodic case study of diesel vehicle drivers exposed to diesel particulate matter in an underground coal mine. Environ. Eng. Res. 2018;23: 265-270.

13. Donaldson K, Stone V, Clouter A, Renwick L, MacNee W. Ultrafine particles. Occup. Environ. Med. 2001;58:211-216.

14. Kwon H, Ryu MH, Carlsten C. Ultrafine particles: unique physicochemical properties relevant to health and disease. Exp. Mol. Med. 2020;52:318-328.

15. Lee KH, Jung HJ, Park DU, et al. Occupational exposure to diesel particulate matter in municipal household waste workers. PLoS one 2015;10(8): e0135229.

16. Shin J, Kim B, Kim HR. Characteristics of occupational exposure to diesel engine exhaust for shipyard transporter signal workers. Int. J. Environ. Res. Public Health 2020;17:4398.

17. Kim SW, Lee GH, Phee YG, et al. Exposure of outdoor workers to particulate matter in construction sites. J. Korean Soc. Occup. Environ. Hyg. 2017;27(1):46-58. [Korean]

18. Nam MR and Phee YG. Exposure assessment of PM10 in expressway toll booths. J. Korean Soc. Occup. Environ. Hyg. 2018;28(2):151-157. [Korean]

19. Kim HR, Kim B, Jo BS, Lee JW. Silica exposure and work-relatedness evaluation for occupational cancer in Korea. Ann. Occup. Environ. Med. 2018;30:4.

20. Jancsek-Turóczi B, Hoffer A, Nyírő-Kósa I, Gelencsér A. Sampling and characterization of resuspended and respirable road dust. J. Aerosol Sci. 2013;65:69-76.

21. Gunawardana C, Goonetilleke A, Egodawatta P, Dawes L, Kokot 
S. Source characterisation of road dust based on chemical and mineralogical composition. Chemosphere 2012;87:163-170.

22. NIOSH: "Method 5040: Diesel Particulate Matter (as Elemental Carbon)." NIOSH Manual of Analytical Methods, 5th ed. National Institute for Occupational Safety and Health, Atlanta, GA, 2016.

23. NIOSH. Guidelines for Air Sampling and Analytical Method Development and Evaluation, Cincinnati, Ohio:NIOSH DHHS 1995.Publication No. 95-117.

24. NIOSH: "Method 7500: SILICA, CRYSTALLINE, by XRD (filter redeposition)" NIOSH Manual of Analytical Methods, 5th ed. National Institute for Occupational Safety and Health, Atlanta, GA, 2016.

25. Kim EA, Lee HE, Kang SK. Occupational burden of cancer in korea. Saf. Health Work 2010;1:61-68.

26. Leem JH, Kim HC, Kim JS, et al. Occupational lung cancer surveillance in south korea, 2006-2009. Saf. Health Work 2010;1:134-139.

27. Choi S, Park D, Kim SW, et al. Estimates of the number of workers exposed to diesel engine exhaust in south korea from 1993 to 2013. Saf. Health Work 2016;7:372-380.

28. Chung Y, Hwang MS, Kim JY. Study of diameter distribution about sizable particles and organic matters at the highway tollgate. Proceedings of the Korea Air Pollution Research Association Conference 1999.04.01:283-84. [Korean]

29. Lee MH, Han EJ, Shin CG, Han JS. A study on the size distribution and chemical component of suspended particulate during the period of sandy dust phenomena. J. Korean Soc. Atmos. Environ. 1988;4(2):57-66. [Korean]
30. Nam MR, Jumg JH, Phee YG. Characteristics of airborne and deposited dust in expressway toll booths. J. Korean Soc. Occup. Environ. Hyg. 2020;30(1):10-17. [Korean]

31. Raj MG, Karthikeyan S. Effect of modes of transportation on commuters' exposure to fine particulate matter (PM2.5) and nitrogen dioxide (NO2) in Chennai, India. Environ. Eng. Res. 2020;25(6):898-907.

32. Kim B, Lee K, Shin J, Kim E. Studies on the concentration of silica in the atmosphere. Institute of Occupation and Environment, Korea Workers' Compensation and Welfare Service Report. 2018. [Korean]

33. Kim D, Jo H, Woo C, Ryu SH, Yoon C. Exposure assessment of black carbon among tollbooth worker at a university. J. Korean Soc. Occup. Environ. Hyg. 2019;29(4):464-476. [Korean]

34. Zhu Y, Hinds WC, Kim S, Sioutas C. Concentration and size distribution of ultrafine particles near a major highway. J. Air Waste Manage. Assoc. 2002;52:1032-1042.

35. Kim C, Kim K, Lee J. Assessment of black carbon concentration as a potential measure of air quality at multi-purpose facilities. J. Aerosol Sci. 2019;138:105450.

36. Andreae M, Gelencs A. Black carbon or brown carbon? The nature of light-absorbing carbonaceous aerosols. Atmos. Chem. Phys. 2006;6(10):3131-3148.

37. Garcia R, Hart JE, Davis ME et al. Effects of wind on background particle concentrations at truck freight terminals. J. Оссир. Environ. Hyg. 2007:4:36-48.

38. DeGaetano AT, Doherty OM. Temporal, spatial and meteorological variations in hourly PM2. 5 concentration extremes in New York City. Atmos. Environ. 2004;38:1547-1558. 